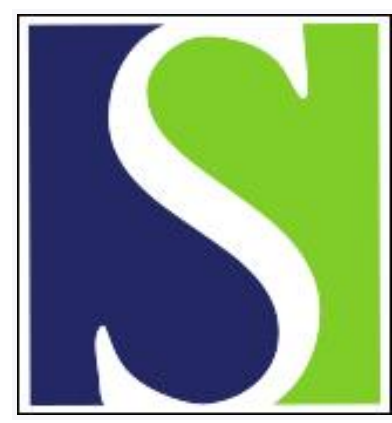

Scand J Work Environ Health 2004;30(6):459-467

https://doi.org/10.5271/sjweh.835

Issue date: Dec 2004

Prognostic factors related to recurrent low-back pain and sickness absence

by van den Heuvel SG, Ariëns GAM, Boshuizen HC, Hoogendoorn WE, Bongers PM

Affiliation: PO Box 718, 2130 AS, Hoofddorp, The Netherlands. S.vdHeuvel@arbeid.tno.nl

Refers to the following texts of the Journal: 1999;25(1):50-56

1999;25(5):387-403 2001;27(4):258-267

The following articles refer to this text: 2018;44(1):25-36;

2018;44(2):156-162

Key terms: cohort study; lifting; posture; psychosocial factor; recurrent low-back pain; sickness absence; workplace

This article in PubMed: www.ncbi.nlm.nih.gov/pubmed/15633597

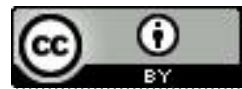




\title{
Prognostic factors related to recurrent low-back pain and sickness absence
}

\author{
by Swenne G van den Heuvel,, ${ }^{1,2}$ Geertje AM Ariëns, ${ }^{2,3}$ Hendriek C Boshuizen, ${ }^{4}$ \\ Wilhelmina E Hoogendoorn, ${ }^{5}$ Paulien M Bongers ${ }^{1,2}$
}

van den Heuvel SG, Ariëns GAM, Boshuizen HC, Hoogendoorn WE, Bongers PM. Prognostic factors related to recurrent low-back pain and sickness absence. Scand J Work Environ Health 2004;30(6):459-467.

\begin{abstract}
Objectives This study aimed at determining the prognostic factors related to the recurrence of low-back pain and future sickness absence due to low-back pain.

Methods Data were used from a prospective cohort study in a working population with a 3-year follow-up period. They were collected with annual questionnaires. A generalized estimating equation model was used to study the relation between pain characteristics, individual characteristics, and work-related factors and the recurrence of low-back pain or sickness absence due to low-back pain in the following year. Adjustments were made for potential confounders.

Results All the pain characteristics [odds ratios (OR) varying from 1.4 to 2.4], flexion and rotation of the upper part of the body [OR 1.6, 95\% confidence interval (95\% CI) 1.1-2.5], low decision authority (OR 1.6, 95\% CI 1.0-2.6), and low job satisfaction (OR 1.5, 95\% CI 1.0-2.3), increased the risk of recurrent low-back pain. High disability due to low-back pain (OR 2.6, 95\% CI 1.2-5.7), low co-worker support (OR 4.1, 95\% CI 1.6-10.5), and low job satisfaction (OR 2.4, 95\% CI 1.3-4.5) were predictors of sickness absence due to low-back pain. Lifting weights did not influence the risk of recurrences or sick leave.

Conclusions According to this study, high disability due to low-back pain is a prognostic factor for recurrent low-back pain and future sickness absence due to low-back pain. In addition, the following work-related factors predict a poor prognosis of low-back pain: flexion or rotation of the trunk, low job satisfaction, low decision authority, and low social support.
\end{abstract}

Key terms study, cohort; lifting; posture; factor, psychosocial; workplace.

Low-back pain is a major health problem in The Netherlands and other Western countries. In a Dutch study, the following 1-year prevalences of self reported lowback pain were found: $41.6 \%$ for men and $46.2 \%$ for women in the Dutch general population aged 25 years and older (1). Low-back pain is also one of the most common work-related health problems. The same study showed that $17 \%$ of the Dutch working population believes that their work causes low-back pain. This is a relatively low value compared with that of other European countries. Overall, approximately $30 \%$ of European workers report that their work causes low-back pain, the rates varying between $13 \%$ and $44 \%$ (2).

The preceding findings indicate that low-back pain is a considerable financial burden to society. Low-back pain can cause sickness absence and (work) disability. The previously mentioned Dutch study reported that $20 \%$ of the people who reported low-back pain also reported sickness absence due to low-back pain (1). Estimates of the total costs of low-back pain in various countries indicate that these costs are $1-2 \%$ of the gross national product (3). The total cost of low-back pain in The Netherlands in 1991 was estimated to be approximately USD 5 billion (ie, 1.7\% of the gross national product) (4).

Results from existing studies suggest that low-back pain typically runs a recurrent course characterized by variation and change (5). The pain usually resolves within 1 month, but recurrences are common (6). Several studies examined pain characteristics as prognostic

1 TNO Work and Employment, Hoofddorp, The Netherlands.

2 Body@Work, Research Center Physical Activity, Work and Health TNO-VU, The Netherlands.

3 Institute for Research in Extramural Medicine, Department of Social Medicine, VU University Medical Center, Amsterdam, The Netherlands.

4 National Institute of Public Health and the Environment, Bilthoven, The Netherlands.

5 The Netherlands Cancer Institute/Antoni van Leeuwenhoek Hospital, Amsterdam, The Netherlands.

Reprint requests to: SG van den Heuvel, PO Box 718, 2130 AS, Hoofddorp, The Netherlands.

[E-mail: S.vdHeuvel@ arbeid.tno.nl] 
factors for these recurrences (7-11), but only a few took place in an occupational setting. Besides the prognostic value of pain characteristics, it would be interesting to know which work-related factors predict recurrent lowback pain, especially in an occupational setting. Above all, these factors can be influenced to benefit a better outcome.

Recently, several of longitudinal studies have been conducted to examine the relationship between workrelated physical and psychosocial load and the occurrence of low-back pain (12-18). Moreover, Hoogendoorn et al $(19,20)$ summarized the literature on risk factors for the occurrence of low-back pain in two systematic reviews. In these studies the identified risk factors for physical load were flexion $(12,18,19)$ and rotation $(12,19)$ of the trunk and lifting $(12,18,19)$. The results for psychosocial characteristics were contradictory.

Whereas studies on work-related risk factors for the occurrence of low-back pain are abundant, few studies could be found concerning the recurrence of low-back pain. Most studies concern patient populations and are focused on chronic disability or return to work (21-27). The work-related prognostic factors that were identified in these studies were the lack of opportunity to take unscheduled breaks (23), lack of stimulating worktasks (24), and various psychosocial factors (25). Moreover, a review of studies concerning biopsychosocial determinants of chronic disability due to low-back pain identified psychosocial work characteristics as prognostic factors (26). However, one of the few studies that took place in an occupational setting did not identify psychosocial factors as prognostic factors (27). Few studies on risk factors for the recurrence of low-back pain have dealt with work-related physical load. In these studies heavy work $(22,26)$, lifting $(23)$, and repetitive work (23) were not identified as prognostic factors.

The purpose of this study was to examine prognostic factors for recurrences of low-back pain and for future sickness absence due to low-back pain in an occupational setting of workers reporting low-back pain. Instead of the prognosis of one low-back pain episode being studied, the prognosis of the course of low-back pain of an individual was focused on.

\section{Study population and methods}

\section{Study population}

In 1994, the Study on Musculoskeletal Disorders, Absenteeism, Stress and Health (SMASH), a large prospective cohort study with a follow-up period of 3 years, was initiated among a working population in The Netherlands. The main purpose of this large-scale study was to determine risk factors for musculoskeletal disorders, with a focus on the low back, neck, and shoulder. A prerequisite for participating companies was that no major reorganizations were planned for the next 3 years and that the turnover rate of the workforce was lower than $15 \%$. The 34 participating companies were asked to select workers who had been employed in their current job for at least 1 year and who were working $\geq 24$ hours a week. The population included blue-collar workers, white-collar workers, and workers in care professions. At baseline, 1789 (87\%) of the 2064 workers invited to participate in SMASH filled out a questionnaire, 1738 of whom were eligible for participation in our study.

\section{Data collection}

After the baseline measurement in 1994, there was a follow-up period of 3 years. Each year, in 1995, 1996, and 1997, a postal questionnaire was sent to the worker's home address. This questionnaire was similar to the baseline questionnaire and contained questions about, among others, low-back pain, work-related physical load, psychosocial work characteristics, and individual characteristics.

Individual characteristics. Data on individual characteristics, age, gender, smoking habits, exercise behavior (28) and coping styles (29), were derived from the baseline questionnaire. Body weight and height were measured by a physiotherapist during the physical examination and were used to calculate the body mass index. Data on exercise behavior were collected at each annual measurement. The other individual characteristics were considered as time-independent variables and were measured at baseline only.

Pain characteristics and disability. Workers who reported low-back symptoms in the previous 12 months were requested to answer an additional number of questions on duration, frequency, radiation, pain intensity, and disability. The mean pain intensity related to the low back was measured with the pain scale of Von Korff (30). Workers who reported low-back pain were asked to rate their mean pain intensity in the last 12 months on an 11-point scale (with 0 being no pain at all and 10 being the most severe pain ever experienced).

Disability due to low-back pain was measured with the disability questionnaire developed by Roland \& Morris (31). The workers who reported low-back pain were requested to answer 24 questions concerning the ability to carry out daily activities, such as getting dressed, walking stairs, bending, or getting out of a chair. A scale score was constructed by counting the activities that workers were unable to perform due to their low-back pain. 
Work-related physical load. Flexion or rotation of the upper part of the body, moving heavy loads of $>25 \mathrm{~kg}$, and driving a vehicle at work was measured with the Dutch Musculoskeletal Questionnaire on a 4-point scale (seldom or never, sometimes, quite often, very often) (32). Physical load variables can vary in time. Therefore, the questions concerning physical load were part of all the annual questionnaires.

Psychosocial work characteristics. A Dutch version of Karasek's Job Content Questionnaire was used to measure the psychosocial work characteristics. Different items of this questionnaire were combined into the five dimensions proposed by Karasek et al (ie, quantitative job demands, decision authority, skill discretion, supervisor support, and co-worker support) (33). The precise calculation of these dimensions has been described by de Jonge et al (34) on the basis of data from our present study. Variables concerning psychosocial work characteristics also can vary in time, so questions concerning them were present in all the annual questionnaires.

Low-back symptoms. Data on low-back symptoms were collected with an adapted version of the Nordic Questionnaire (35). At each measurement, the workers were asked to rate the occurrence of low-back symptoms in the previous 12 months on a 4-point scale (seldom or never, sometimes, regular, prolonged). They were identified as cases of recurrent low-back pain if they reported regular or prolonged low-back pain in the previous 12 months in two successive measurements.

Sickness absence. The companies were asked to register sickness absence during the time of the study. For only of 21 of the 34 companies, were complete data obtained. From these 21 companies, 1080 workers (89\%) had given their informed consent to register their sick leave specifically for this study. Physicians of the occupational health services coded the reasons for absence according to an adapted Dutch version (36) of the International Classification of Diseases (ICD) (37). The following diagnoses were considered to constitute sickness absence due to low-back pain: lumbosacral spondylosis and spondylosis of an unspecified site (ICD numbers $721,721.3,721.42,721.9$ ), lumbar intervertebral disc disorders and intervertebral disc disorders of an unspecified site (ICD numbers 722, 722.10, 722.2, 722.52,
722.6, 722.73, 722.9), and other and unspecified back disorders (ICD numbers 724, 724.2, 724.3, 724.4, 724.5, 724.9).

\section{Statistical analysis}

Exposure to work-related risk factors could change due to low-back pain. A change in exposure could change the relationship between exposure and outcome. Therefore, as a preliminary step in the analysis, we examined whether a change in exposure occurred between the time of exposure and the time of the outcome measurement and whether this was a favorable or unfavorable change, apart for workers with and without regular low-back pain at the time of exposure measurement.

To determine the prognostic factors for the recurrence of low-back pain, the relation was studied between the exposure variables at one point in time and the outcome variables 1 year later (figure 1). As can be seen in figure 1, for each worker, a maximum of three combinations of exposure and outcome data were available. However, for each combination, only the workers reporting regular or prolonged low-back pain in the previous 12 months at the time of the exposure measurement were included in the analyses. The outcome measures were the recurrent 12-month prevalence of regular or prolonged low-back pain at the next measurement in the following year and sickness absence due to low-back pain in the following year. Work-related physical load, psychosocial work characteristics, pain characteristics, and disability were defined as the independent variables. The time-independent individual characteristics were regarded as the covariates.

As one person could contribute several observations, the generalized estimating equation (GEE), developed by Liang \& Zeger, was applied (38), as this method is suitable for dependent observations. The Proc Genmod procedure in the statistical package SAS (version 6.12) (39) was used. Since the outcome under study was dichotomous, the link-function in Proc Genmod was specified as logistic. The working correlation structure for the repeated measurements of the outcome variable was specified as exchangeable, implying that all correlations of the outcome variable were assumed to be equal, irrespective of the time-period between the measurements. The exchangeable correlation structure is the most neutral option $(14,38,40)$.

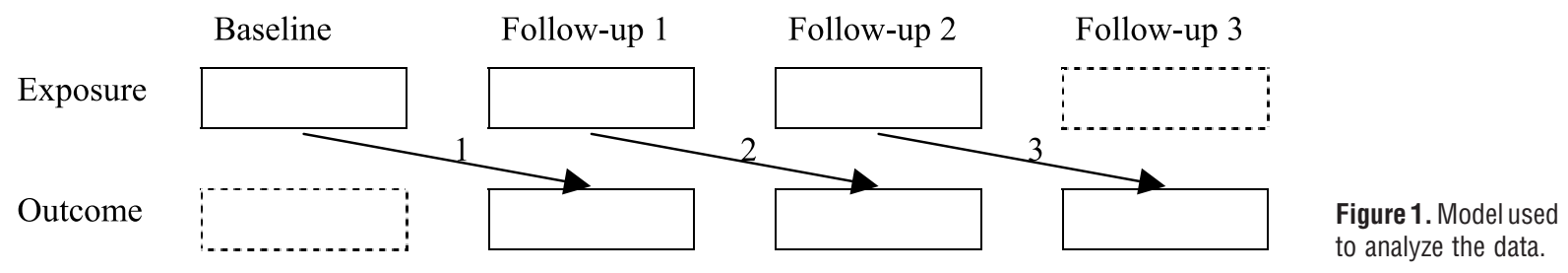


Univariate analyses and multivariate analyses were carried out, the result being odds ratios with corresponding $95 \%$ confidence intervals for all the variables tested. Before the testing, the multivariate model correlations were checked to avoid collinearity.

\section{Results}

An overview of the changes in the exposures is given in table 1 for the workers with and without low-back pain. It shows that there were no differences between those with and those without low-back pain in the change of exposure.

At baseline, 534 workers reported regular or prolonged low-back pain. At the first and second follow-up measurements, regular or prolonged low-back pain was reported by 395 and 379 workers, respectively, resulting

Table 1. Overview of changes in exposure between subsequent follow-up measurements for workers with regular or prolonged low-back pain and for workers with seldom-never or sometimes low-back pain.

\begin{tabular}{|c|c|c|c|}
\hline Exposure & $\begin{array}{l}\text { Favorable } \\
\text { change }^{a}\end{array}$ & $\begin{array}{c}\text { No } \\
\text { change }\end{array}$ & $\begin{array}{c}\text { Unfavorable } \\
\text { change }\end{array}$ \\
\hline \multicolumn{4}{|l|}{ Driving a vehicle } \\
\hline No low-back pain & 10 & 78 & 12 \\
\hline Low-back pain & 10 & 76 & 15 \\
\hline \multicolumn{4}{|c|}{ Flexion or rotation of the upper part of the body } \\
\hline No low-back pain & 22 & 68 & 11 \\
\hline Low-back pain & 25 & 64 & 12 \\
\hline \multicolumn{4}{|l|}{ Moving of heavy loads } \\
\hline No low-back pain & 9 & 84 & 8 \\
\hline Low-back pain & 12 & 80 & 9 \\
\hline \multicolumn{4}{|c|}{ Quantitative job demands } \\
\hline No low-back pain & 16 & 65 & 19 \\
\hline Low-back pain & 15 & 68 & 17 \\
\hline \multicolumn{4}{|l|}{ Decision authority } \\
\hline No low-back pain & 18 & 65 & 17 \\
\hline Low-back pain & 17 & 65 & 18 \\
\hline \multicolumn{4}{|l|}{ Skill discretion } \\
\hline No low-back pain & 14 & 71 & 15 \\
\hline Low-back pain & 15 & 71 & 13 \\
\hline \multicolumn{4}{|l|}{ Co-worker support } \\
\hline No low-back pain & 13 & 70 & 17 \\
\hline Low-back pain & 15 & 68 & 17 \\
\hline \multicolumn{4}{|l|}{ Supervisor support } \\
\hline No low-back pain & 16 & 64 & 20 \\
\hline Low-back pain & 17 & 62 & 20 \\
\hline \multicolumn{4}{|l|}{ Job satisfaction } \\
\hline No low-back pain & 16 & 65 & 19 \\
\hline Low-back pain & 17 & 59 & 23 \\
\hline
\end{tabular}

in 1308 reports of regular or prolonged low-back pain at the defined time of exposure (figure 1), corresponding to a population of 778 subjects. Data on the outcome measurement "regular or prolonged low-back pain" in the following year were available for 1142 observations. In these observations $57 \%$ reported the recurrence of low-back pain in the following year. Data on the outcome measurement "sickness absence in the following year" were available for 629 observations. In these observations $18 \%$ had $\geq 1$ days of sickness absence due to low-back pain.

\section{Individual characteristics, pain characteristics and disability}

Table 2 gives the individual characteristics, pain characteristics, and disability of the observations of regular or prolonged low-back pain at the time of exposure. The odds ratios are presented for the recurrence of low-back pain and sickness absence due to low-back pain in the following year. Table 2 shows that no individual characteristics were found that predict low-back pain or sickness absence in the following year. The adjustment for physical and psychosocial factors hardly changed the results, apart from the odds ratio for a high support-seeking coping style and low-back pain. After adjustment, this odds ratio was considerably higher and bordered on statistical significance.

Almost all of the pain characteristics were identified as prognostic factors for the recurrence of low-back pain, as well as future sickness absence due to low-back pain. However, a long duration of the pain episode, a high pain intensity, and radiating pain were not prognostic factors for future sickness absence after adjustment for other factors. A high score on disability was the best predictor for both outcomes.

\section{Work-related physical load}

Table 3 presents the distribution of the variables concerning work-related physical load and the crude and adjusted odds ratios for these factors and the recurrence of low-back pain and sickness absence due to low-back pain in the following year. Table 3 shows that flexion and rotation of the upper part of the body were prognostic factors for the recurrence of low-back pain, but not for sickness absence in the following year. Moving heavy loads turned out to have no effect on future recurrences or sickness absence.

\section{Psychosocial work characteristics}

Table 4 presents the distribution of the variables concerning psychosocial work characteristics and the odds ratios of these variables for the recurrence of low-back 
Table 2. Crude and adjusted odds ratios (OR) and corresponding $95 \%$ confidence intervals $(95 \% \mathrm{Cl})$ for the individual characteristics and pain characteristics resulting from analyses with a general linear equation (GEE) for the population reporting regular or prolonged low-back pain at the time of exposure ( $\mathrm{N}=778$ workers) with regular or prolonged low-back pain and sickness absence due to low-back pain in the following year as the outcome variable.

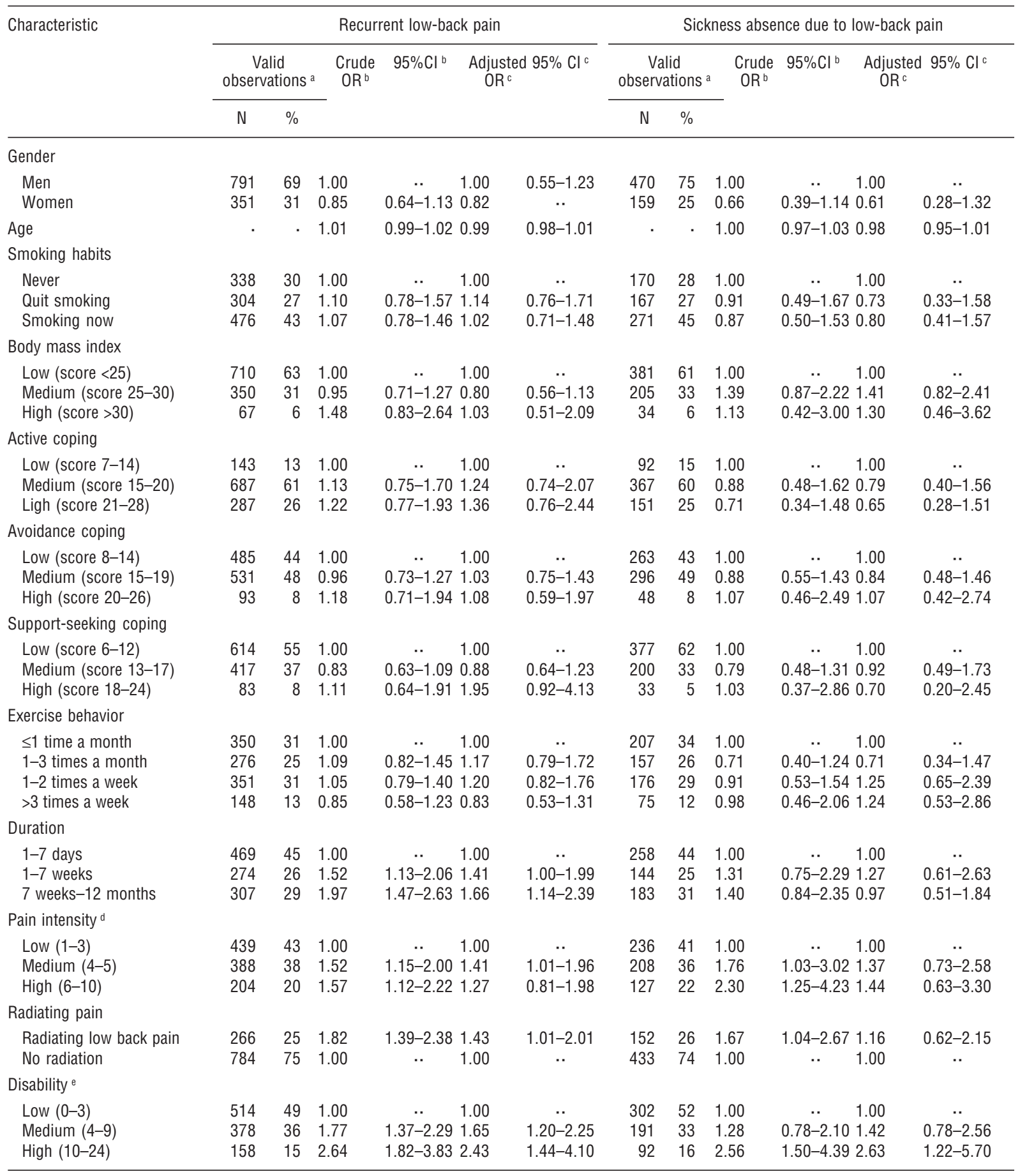

a Observations for which neither the exposure variable nor the outcome variable are missing.

b Crude OR and $95 \% \mathrm{Cl}$ resulting from univariate the GEE analysis.

${ }^{c}$ Adjusted $\mathrm{OR}$ and $95 \% \mathrm{Cl}$ resulting from the multivariate GEE analysis, adjustment having been made for the other individual characteristics and pain characteristics, the work-related physical load variables, and psychosocial work characteristics.

d11-point scale: $0=$ no pain at all, $10=$ most severe pain ever experienced.

e 24-point scale referring to the disability to carry out daily activities: $0=$ no disability, $24=$ not able to carry out any of the mentioned activities. 
Table 3. Crude and adjusted odds ratios (OR) and corresponding $95 \%$ confidence intervals $(95 \% \mathrm{Cl})$ for the work-related physical load variables, resulting from analyses with a general linear equation (GEE) for the population reporting regular or prolonged low-back pain at the time of exposure ( $\mathrm{N}=778$ workers) with regular or prolonged low-back pain in the following year as the outcome variables.

\begin{tabular}{|c|c|c|c|c|c|c|c|c|c|c|c|c|}
\hline \multirow[t]{3}{*}{ Variable } & \multicolumn{6}{|c|}{ Recurrent low-back pain } & \multicolumn{6}{|c|}{ Sickness absence due to low-back pain } \\
\hline & \multicolumn{2}{|c|}{$\begin{array}{c}\text { Valid } \\
\text { observations }{ }^{a}\end{array}$} & \multirow[t]{2}{*}{$\begin{array}{c}\text { Crude } \\
\mathrm{OR}^{\mathrm{b}}\end{array}$} & \multirow[t]{2}{*}{$95 \% \mathrm{Cl}$} & \multicolumn{2}{|c|}{$\begin{array}{l}\text { Adjusted } 95 \% \mathrm{Cl}^{\mathrm{c}} \\
\quad \mathrm{OR}^{\mathrm{c}}\end{array}$} & \multicolumn{2}{|c|}{$\begin{array}{c}\text { Valid } \\
\text { observations }{ }^{\text {a }}\end{array}$} & \multirow[t]{2}{*}{$\begin{array}{c}\text { Crude } \\
\mathrm{OR}^{\mathrm{b}}\end{array}$} & \multirow[t]{2}{*}{$95 \% \mathrm{Cl}^{\mathrm{b}}$} & \multirow[t]{2}{*}{$\begin{array}{l}\text { Adjusted } \\
\mathrm{OR}^{\mathrm{c}}\end{array}$} & \multirow[t]{2}{*}{ d $95 \% \mathrm{Cl}^{\mathrm{c}}$} \\
\hline & $\mathrm{N}$ & $\%$ & & & & & $\mathrm{~N}$ & $\%$ & & & & \\
\hline \multicolumn{13}{|l|}{ Driving a vehicle } \\
\hline Never or sometimes & 968 & 86 & 1.00 & .. & 1.00 & .. & 527 & 85 & 1.00 & .. & 1.00 & .. \\
\hline Quite often or very often & 154 & 14 & 1.11 & $0.75-1.63$ & 1.20 & $0.76-1.89$ & 94 & 15 & 1.21 & $0.67-2.20$ & 1.23 & $0.56-2.69$ \\
\hline \multicolumn{13}{|c|}{ Flexion or rotation of the upper part of the body } \\
\hline Seldom or never or sometimes & 567 & 50 & 1.00 & 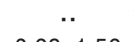 & 1.00 &.. & 308 & 50 & 1.00 &.. & 1.00 & .. \\
\hline Quite often & 359 & 32 & 1.21 & $0.92-1.59$ & 1.17 & $0.83-1.65$ & 197 & 32 & 1.19 & $0.72-1.96$ & 0.87 & $0.47-1.60$ \\
\hline Very often & 198 & 18 & 1.80 & $1.29-2.51$ & 1.63 & $1.05-2.54$ & 116 & 19 & 1.24 & $0.72-2.14$ & 40.92 & $0.43-1.96$ \\
\hline \multicolumn{13}{|l|}{ Moving heavy loads (>25 kg) } \\
\hline Seldom or never or sometimes & 857 & 76 & 1.00 &.$\cdot$ & 1.00 &.. & 485 & 78 & 1.00 &.. & 1.00 & .. \\
\hline Quite often & 172 & 15 & 1.29 & $0.92-1.81$ & 1.25 & $0.81-1.92$ & 83 & 13 & 0.78 & $0.38-1.60$ & 0.70 & $0.29-1.65$ \\
\hline Very often & 98 & 9 & 1.28 & $0.82-1.98$ & 1.14 & $0.67-1.94$ & 55 & 9 & 0.90 & $0.42-1.93$ & 30.65 & $0.25-1.69$ \\
\hline
\end{tabular}

Table 4. Crude and adjusted odds ratios (OR) and corresponding $95 \%$ confidence intervals $(95 \% \mathrm{Cl})$ for the psychosocial work characteristics resulting from analyses with a general linear equation (GEE) with the population reporting regular or prolonged low-back pain at the time of exposure ( $\mathrm{N}=778$ workers) with regular or prolonged low-back pain and sickness absence due to low-back pain in the following year as the outcome variables.

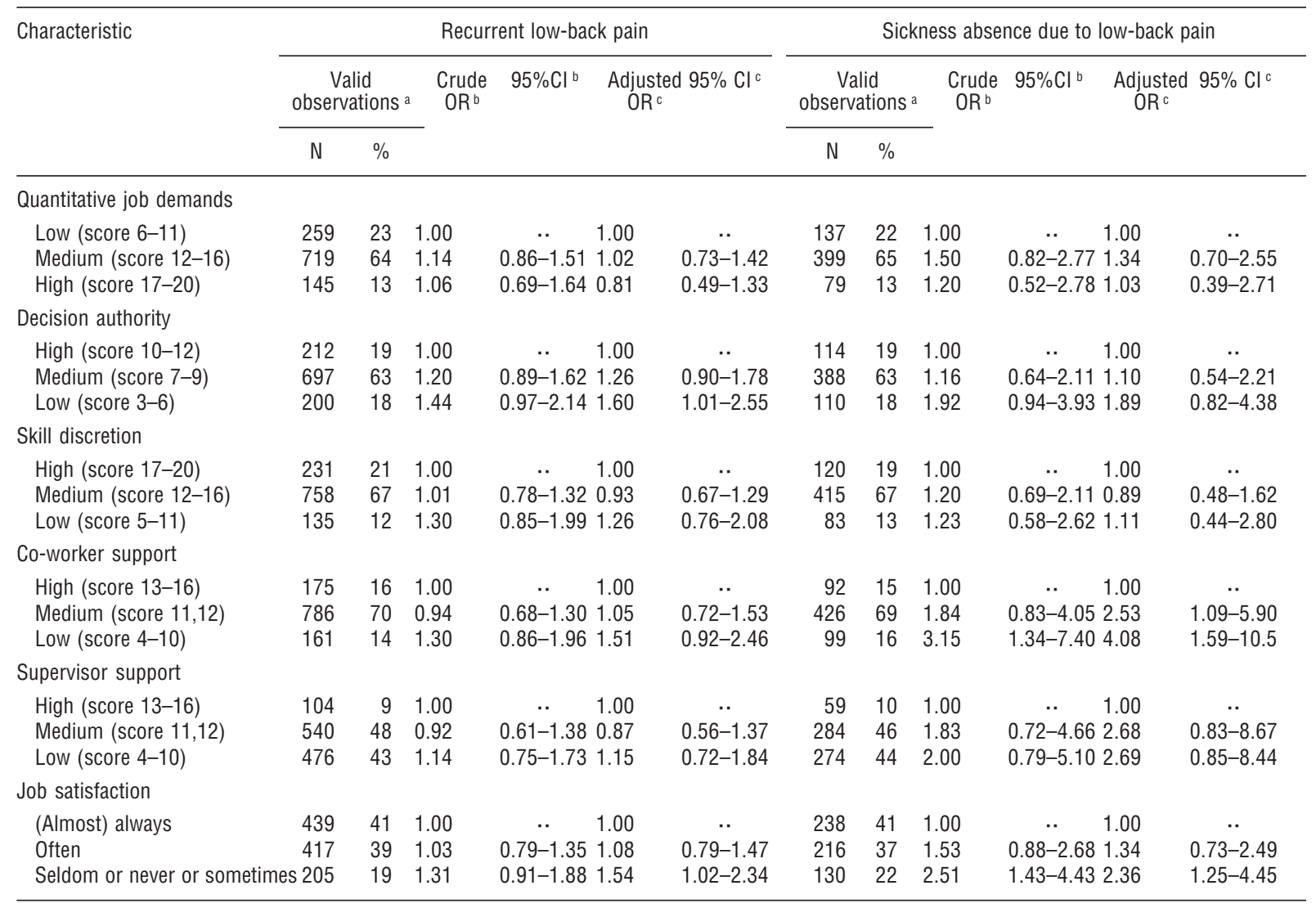

a Observations for which neither the exposure variable nor the outcome variable are missing.

${ }^{b}$ Crude $\mathrm{OR}$ and $95 \% \mathrm{Cl}$ resulting from the univariate GEE analysis.

${ }^{c}$ Adjusted $\mathrm{OR}$ and $95 \% \mathrm{Cl}$ resulting from the multivariate GEE analysis, adjustment having been made for the work-related physical load variables, pain characteristics, and the following individual characteristics: gender, age, smoking habits, body mass index, exercise behavior, and coping skills. 
pain and sickness absence due to low-back pain in the following year. The table shows that, after adjustment for physical load and individual characteristics, low job satisfaction was a prognostic factor for both recurrent low-back pain and sickness absence due to low-back pain in the following year. Low decision authority was a prognostic factor for recurrent low-back pain, but the odds ratio of this factor for sickness absence, although higher, was not statistically significant. Both co-worker support and supervisor support seemed to be more relevant in the prognosis of sickness absence than in that of recurrent low-back pain. However, only the odds ratio for co-worker support and sickness absence was statistically significant.

\section{Discussion}

\section{Summary of findings}

Pain characteristics were identified as predictors of a poor prognosis for workers with low-back pain. High disability due to low-back pain turned out to be the best predictor of future low-back pain, as well as sickness absence due to this pain. None of the individual characteristics could be identified as prognostic factors.

In a working population, it is especially important to identify work-related prognostic factors as these factors can be altered to reduce the risk of a poor outcome. In this study driving a vehicle and moving heavy loads were not identified as prognostic factors, whereas flexion and rotation of the trunk were identified as prognostic factors for recurrent low-back pain, but not for future sickness absence due to this pain. Low job satisfaction was identified as a prognostic factor for both recurrent low-back pain and sickness absence due to lowback pain in the following year. Other prognostic factors were low decision authority, low co-worker support, and low supervisor support, but these factors were not statistically significant for either outcome.

Our results can be compared with those of other analyses with the same data, dealing with risk factors for the onset of low-back pain (12-14) and the occurrence of sickness absence due to low-back pain (15). In those analyses the study population consisted of workers who did not report low-back pain at baseline. Both flexion and rotation of the trunk and lifting weights were risk factors for the occurrence of low-back pain $(12,14)$, as well as sickness absence due to low-back pain (15). Concerning psychosocial work characteristics low job satisfaction was identified as a risk factor for sickness absence due to low-back pain (15), while no statistically significant relations were found between psychosocial work characteristics and the occurrence of low-back pain $(13,14)$. However, indications were found of a relationship between low social support and low-back pain, as well as sickness absence due to low-back pain $(13,15)$.

From these studies it appears that flexion or rotation of the upper part of the body could be identified as prognostic factors for the occurrence and recurrence of low-back pain. With regard to flexion and rotation, it should be noted that the exposure to these factors did not change due to complaints of the low-back (table 1). It seems that workers keep working in this unfavorable posture in spite of their (former) complaints. It is not clear why flexion and rotation predict recurrent lowback pain but not future sickness absence in a population of workers with complaints, whereas it was identified as a prognostic factor for both symptoms and sickness absence in a symptom-free population.

With regard to moving heavy loads, it could be assumed that the exposure to this factor differs for workers with and without low-back pain. For example, workers with (a recent history of) low-back pain who need to lift weights may perform this task in a manner other than that used by workers who have never experienced low-back pain. With regard to the psychosocial factors, it could be assumed that it is not that obvious to change these conditions, as the relation to low-back pain is not clear.

It appears that physical risk factors for the occurrence and recurrence of low-back pain are similar. This finding is not surprising, as it is plausible that the causes of a new episode of low-back pain have caused the first episode as well. On the other hand, one might suspect that, as a consequence of the complaints, one would change the unfavorable work conditions. In such a case, especially the risk factors concerning physical load would not be identified as major risk factors for the recurrence of the complaints. However, this assumption appears to be incorrect.

Psychosocial work characteristics appear to predict both the occurrence and recurrence of low-back pain. However, in this study population, the relation with recurrence and future sickness absence appears to be stronger than the relation with first onset of low-back pain.

\section{Comparison with previous findings}

Concerning pain characteristics and disability, similar results were found in previous studies. In a review of studies, based, to a large extent, on patient surveys with return to work as the outcome measure (11), disability was identified as a significant prognostic factor for a poor prognosis, as well as pain severity. In another study, based on the results of patients in primary care (8), initial disability rather than initial pain intensity 
seemed predictive of poor recovery. In one study, based on a working population (10), disability was identified as the best predictor of future pain, whereas, in another study in a working population (7), disability was one of the best predictors of absenteeism but not of symptoms.

Previous studies concerning the recurrence of lowback pain did not examine flexion or rotation or lifting weights as a prognostic factor. Other variables concerning physical load (heavy work, lifting, and repetitive work), examined in these studies, were not identified as prognostic factors $(22,23,26)$. The results of other studies on the prognostic value of psychosocial work characteristics were rather ambiguous. Furthermore, the comparison of these studies is sometimes difficult as different operationalizations of psychosocial factors were applied.

\section{Limitations and potential sources of bias}

The model used in our study is a time-lag model, implying that the repeated measurements of the exposure were related to outcome reported at one measurement point later (40). With the use of such a time-lag model, the temporal sequence of cause and effect is taken into account. In this model the time lag of 1 year was studied. However, it is not known if this is an appropriate time lag. Moreover, it could be possible that the different variables need to be studied in different time-lag models. For example, psychosocial work characteristics may have a more short-term effect, whereas work-related physical load may have a more long-term effect. It was beyond the scope of this study to explore these alternatives.

In the analyses, the correlation structure was specified as exchangeable. To examine whether the results are strongly susceptible with respect to the choice of correlation structure, we repeated the analyses with an unstructured correlation structure. However, the results with an unstructured correlation structure were practically identical to the results with an exchangeable correlation structure.

A potential bias is "feedback bias" (41). It implies that earlier outcomes may affect subsequent exposure. Table 1 shows that workers with and without low-back pain do not differ in the change of exposure between subsequent follow-up measurements. It seems that the complaints do not affect work conditions. Therefore, no effect of feedback bias was expected, although it may be possible that the effect of complaints on exposure could not be demonstrated with our data. For example, workers with low-back pain may not change the frequency in which they move heavy loads, but, as mentioned earlier, they may lift them in another manner than workers without low-back pain.

\section{Concluding remarks}

High disability due to low-back pain was identified as a prognostic factor for recurrent low-back pain and future sickness absence due to low-back pain. With respect to work-related physical factors, flexion and rotation of the trunk were identified as prognostic factors for the recurrence of low-back pain, but not for future sickness absence due to low-back pain. With respect to work-related psychosocial factors, an unfavorable psychosocial work environment (low decision authority, low social support, and low job satisfaction) appeared to predict a poor prognosis of low-back pain, especially future sickness absence.

\section{References}

1. Picavet HSJ, van Gils HWV, Schouten JSAG. Klachten van het bewegingsapparaat in de Nederlandse bevolking: prevalenties, consequenties en risicogroepen [Musculoskeletal complaints in the Dutch population: prevalences, consequences and risk groups]. Bilthoven [The Netherlands]: National Institute of Public Health and the Environment; 2000.

2. Paoli P. Second European survey on working conditions. Dublin: European Foundation for the Improvement of Living and Working Conditions; 1997.

3. Norlund AI, Waddell G. Cost of back pain in some OECD countries. In: Nachemson A, Jonsson E, editors. Neck and back pain: the scientific evidence of causes, diagnosis, and treatment. Philadephia (PA): Lippincott Williams \& Wilkins; 2000:421-5.

4. Van Tulder MW, Koes BW, Bouter LM. A cost-of-illness study of back pain in the Netherlands. Pain 1995;62:233-40.

5. Von Korff M, Saunders K. The course of back pain in primary care. Spine 1996;21:2833-9.

6. Pengel LH, Herbert RD, Maher CG, Refshauge KM. Acute low back pain: systematic review of its prognosis. BMJ 2003;327:323.

7. Rossignol M, Lortie M, Ledoux E. Comparison of spinal health indicators in predicting spinal status in a 1-year longitudinal study. Spine 1993;18:54-60.

8. Coste J, Delecoeuillerie G, Cohen de Lara A, LeParc JM, Paolaggi JB. Clinical course and prognostic factors in acute low back pain: an inception cohort study in primary care practice. BMJ 1994;308:577-80.

9. Hoogen HJM, Koes BW, Devillé W, van Eijk JTM, Bouter LM. The prognosis of low back pain in general practice. Spine 1997;22:1515-21.

10. Estlander AM, Takala EP, Viikari-Juntura E. Do psychological factors predict changes in musculoskeletal pain? J Occup Environ Med 1998;5:445-53.

11. Shaw WS, Pransky G, Fitzgerald TE. Early prognosis for low back disability: intervention strategies for health care providers. Disabil Rehabil 2001;23:815-28.

12. Hoogendoorn WE, Bongers PM, de Vet HCW, Douwes M, Koes BW, Miedema MC, et al. Flexion and rotation of the trunk and lifting at work are risk factors for low back pain: results of a prospective cohort study. Spine 2000;25:3087-92.

13. Hoogendoorn WE, Bongers PM, de Vet HCW, Houtman ILD, Ariëns GAM, van Mechelen W, et al. Psychosocial work 
characteristics and psychological strain in relation to lowback pain. Scand J Work Environ Health 2001;27:258-67.

14. Hoogendoorn WE, Bongers PM, de Vet HCW, Twisk JWR, van Mechelen W, Bouter LM. Comparison of two different approaches for the analysis of data from a prospective cohort study: an application to work related risk factors for low back pain. Occup Environ Med 2002;59:459-65.

15. Hoogendoorn WE, Bongers PM, de Vet HCW, Ariëns GA, van Mechelen W, Bouter LM. High physical work load and low job satisfaction increase the risk of sickness absence due to low back pain: results of a prospective cohort study. Occup Environ Med 2002;59:323-8.

16. Kerr MS, Frank JW, Shannon HS, Norman RW, Wells RP, Neumann WP, et al. Biomechanical and psychosocial risk factors for low back pain at work. Am J Public Health 2001;91:1069-75.

17. Stevenson JM, Weber CL, Smith, JT, Dumas GA, Albert WJ. A longitudinal study of the development of low back pain in an industrial population. Spine 2001;12:1370-7.

18. Vingård E, Alfredsson L, Hagberg M, Kilbom Å, Theorell T, Waldenström M. To what extent do current and past physical and psychosocial occupational factors explain careseeking for low back pain in a working population?: results from the musculoskeletal intervention center-Norrtälje Study. Spine 2000;4:493-500.

19. Hoogendoorn WE, van Poppel MNM, Bongers PM, Koes BW, Bouter LM. Physical load during work and leisure time as risk factors for back pain [review]. Scand J Work Environ Health 1999;25:387-403.

20. Hoogendoorn WE, van Poppel MNM, Bongers PM, Koes BW, Bouter LM. Systematic review of psychosocial factors at work and private life as risk factors for back pain. Spine 2000;25:2114-25.

21. Cats-Baril WL, Frymoyer JW. Identifying patients at risk of becoming disabled because of low back pain. Spine 1991;6:605-7.

22. Gatchel RJ, Polatin PB, Mayer TG. The dominant role of psychosocial risk factors in the development of chronic low back pain disability. Spine 1995;20:2702-9.

23. Infante-Rivard C, Lortie M. Prognostic factors for return to work after a first compensated episode of back pain. Occup Environ Med 1996;53:488-94.

24. Seferlis T, Németh G, Carlsson A. Prediction of functional disability, recurrences, and chronicity after 1 year in 180 patients who required sick leave for acute low back pain. J Spinal Disord 2000;13:470-7.

25. Symonds TL, Burton AK, Tillotson KM, Main CJ. Do attitudes and beliefs influence work loss due to low back trouble? Occup Med 1996;46:25-32.

26. Truchon M, Fillion L. Biopsychosocial determinants of chronic disability and low-back pain: a review. J Occup Rehabil
2000;10:117-42.

27. van der Weide WE, Verbeek JHAM, Sallé HJA, van Dijk FJH. Prognostic factors for chronic disability from acute lowback pain in occupational health care. Scand J Work Environ Health 1999;25:50-6.

28. Godin G, Jobin J, Bouillon J. Assessment of leisure time exercise behavior by self-report: a concurrent validity study. Can J Public Health 1986;77:359-62.

29. Schreurs PJG, van der Willige G, Tellegen B, Brosschot JF. De Utrechtse Coping Lijst: UCL-handleiding. [The Utrecht coping list: UCL-manual]. Lisse (The Netherlands): Swets \& Zeitlinger; 1988.

30. Von Korff M, Ormel J, Keefe FJ, Dworkin SF. Grading the severity of pain. Pain 1992;50:133-49.

31. Roland M, Morris R. A study of the natural history of back pain, part 1: development of a reliable and sensitive measure of disability on low-back pain. Spine 1983;8:141-4.

32. Hildebrandt VH, Bongers PM, van Dijk FJ, Kemper HC, Dul J. Dutch musculoskeletal questionnaire: description and basic qualities. Ergonomics 2001;44:1038-55.

33. Karasek R. Job Content instrument users guide: revision 1.1. Los Angeles (CA): Department of Industrial and Systems Engineering, University of Southern California; 1985.

34. Jonge J de, Reuvers MMEN, Houtman ILD, Bongers PM, Kompier MAJ. Linear and nonlinear relations between psychosocial job characteristics, subjective outcomes, and sickness absence: baseline results from SMASH. J Occup Health Psychol 2000;5:256-68.

35. Kuorinka I, Jonsson B, Kilbom ^̊, Vinterberg H, BieringSørensen F, Andersson G, et al. Standardised Nordic questionnaire for the analysis of musculoskeletal symptoms. Appl Ergon 1987;18:233-7.

36. Gemeentelijk administratiekantoor (GAK). Gedifferentieerd diagnosecode systeem [Differentiated diagnosis code system]. Amsterdam: GAK; 1990.

37. World Health Organization (WHO). International classification of diseases 1975 revision, Volume 1. Geneva: WHO; 1977.

38. Liang K-Y, Zeger SL. Longitudinal data analysis using generalized linear models. Biometrika 1986;73:13-22.

39. SAS Institute Inc. SAS/STAT® Software: changes and enhancements through release 6.12. Cary (NC): SAS Institute Inc; 1997.

40. Twisk JWR. Different statistical models to analyze epidemiological observational longitudinal data: an example from the Amsterdam Growth and Health Study. Int J Sports Med 1997;18:S216-S224.

41. Eisen EA. Methodology for analyzing episodic events. Scand J Work Environ Health 1999;25 Suppl 4:36-42.

Received for publication: 5 February 2004 